\title{
TUBERCULOSE BOVINA EM PROPRIEDADE RURAL NO MUNICÍPIO DE SEROPÉDICA, RIO DE JANEIRO, BRASIL: RELATO DE CASO
}

\author{
(Bovine tuberculosis in rural property in the Seropédica municipality, Rio de Janeiro, Brazil: Case report)
}

${ }^{1}$ Lília Aparecida Marques da Silva, ${ }^{2}$ Marina Sereno de Freitas, ${ }^{1}$ Julio Cesar da Silva Cicarino, ${ }^{2} J a c i$ de Almeida

${ }^{1}$ Secretaria de Estado de Agricultura, Pecuária, Pesca e Abastecimento, Núcleo de Defesa Agropecuária do Rio de Janeiro, Rio de Janeiro, Brasil. ${ }^{2}$ Medicina Veterinária Iniciativa privada, Seropédica, Rio de Janeiro, Brasil.

*Correspondência: lamsvet@yahoo.com.br

RESUMO: A tuberculose é uma das principais doenças infecciosas de importância econômica em bovídeos, podendo acometer outras espécies de animais e inclusive o homem, causando perdas econômicas ao setor de produção, além de ocasionar agravos à saúde pública. É uma zoonose de notificação obrigatória que no Brasil possui um programa de controle e erradicação instituído pelo Ministério da Agricultura, Pecuária e Abastecimento (MAPA), o Programa Nacional de Controle e Erradicação da Brucelose e Tuberculose (PNCEBT) dos bovídeos, que tem por objetivo principal a redução da prevalência e da incidência da brucelose e tuberculose nessas espécies. O Núcleo de Defesa Agropecuária (NDA) do Rio de Janeiro da Secretaria de Estado de Agricultura, Pecuária, Pesca e Abastecimento (SEAPPA) do Rio de Janeiro é responsável pelas ações de vigilância veterinária oficial no município de Seropédica. O presente trabalho tem por objetivo relatar a ocorrência de um foco de tuberculose no município de Seropédica e as ações executadas pelo serviço de vigilância oficial da SEAPPA. No ano de 2020, os técnicos do NDA Rio de Janeiro receberam o informe de notificação com laudo laboratorial positivo para tuberculose, pela técnica de histoquímica em seções de pulmão e encéfalo, de uma fêmea bovina da raça Girolando, com aproximadamente seis anos, necropsiada numa propriedade rural localizada no município de Seropédica. Após a notificação, o serviço oficial realizou a vistoria da propriedade e solicitou ao produtor que realizasse a tuberculinização nos demais animais conforme prevê o regulamento do PNCEBT. Houve a notificação imediata às Secretarias Municipais de Saúde e Agricultura do município de Seropédica para as providências junto ao produtor e demais envolvidos, haja vista que as medidas com relação aos animais na propriedade já haviam sido executadas pelo serviço oficial de modo a debelar o foco. Com a apresentação do atestado de exames negativos ao teste de tuberculinização comparativo simples dos demais bovinos do plantel, foi encerrado o foco na propriedade. Conclui-se que a tuberculose bovina está presente no estado do Rio de Janeiro, e que necessita da conscientização tanto por parte dos médicos veterinários quanto dos produtores para maior adesão do PNCEBT, controlando assim a enfermidade nos rebanhos. Há a necessidade da realização de um estudo epidemiológico para conhecimento da prevalência da tuberculose no estado por se tratar de uma questão de saúde pública, uma vez que os testes de tuberculinização são obrigatórios apenas para fins de trânsito para as finalidades reprodução e participação em eventos agropecuários, existindo vários criatórios que não realizam exames e assim, outros focos podem existir devido à prática da troca de animais principalmente entre os pequenos produtores.

Palavras-chave: controle; diagnóstico; saúde pública.

\section{Referências}

BRASIL. Ministério da Agricultura, Pecuária e Abastecimento. Instrução Normativa $n^{\circ}$ 50, de 24 de setembro de 2013. Altera a lista de doenças passíveis da aplicação de medidas de defesa sanitária animal. Diário Oficial da União, Brasília, DF, de 25/09/2013, Seção 1. 2013.

Instrução Normativa $n^{\circ} 10$, de 03 de março de 2017. Estabelece o Regulamento Técnico do Programa Nacional de Controle e Erradicação da Brucelose e da Tuberculose Animal PNCEBT e a Classificação das Unidades da Federação de acordo com o grau de risco para as doenças brucelose e tuberculose, assim como a definição de procedimentos de defesa sanitária animal a serem adotados de acordo com a classificação, na forma desta Instrução Normativa. Diário Oficial da União, Brasília, DF, de 20/06/2017, Edição 116, Seção 1, p. 4. 2017. 